\title{
O ESPELHO DE CRISTINA (Séc. XV)
}

\author{
Manuela Mendonça* \\ manuela.mendonca@sapo.pt
}

RESUMO: A segunda metade do século XV ficou marcada, em Portugal, pelo interesse manifestado pela educação/instrução feminina. É a partir dessa época que encontramos na corte uma grande preocupação pelo protocolo e pela erudição. Uma das obras que mais divulgação teve foi o Espelho de Cristina, ou Livro das Três Virtudes, da autoria de Cristina de Pisano. D. Isabel, mulher de D. Afonso V, mandou-o traduzir para português cerca de 1450. Posteriormente, uma outra Rainha, D. Leonor, mandaria fazer a respectiva publicação. Neste trabalho fazemos uma abordagem à problemática da educação da Mulher em Portugal e procuramos confrontá-la com os ensinamentos desse livro, apresentando alguns exemplos que nos parece ilustrarem o reflexo desses ensinamentos na actuação de algumas senhoras da Corte.

PALAVRAS-CHAVE: corte, educação, protocolo, espelho, moral.

1.Se há aspectos ignorados, não apenas na História de Portugal, mas também na História da Europa, na época medieval, um deles é, sem dúvida, a temática ligada à educação. Refiro-me à educação enquanto formação, não apenas intelectual, mas também moral. E nesta poderia ainda distinguir entre a educação dos diversos grupos sociais e na necessária diferença entre a que se dirigia a homens e a mulheres. Fixandonos na educação masculina do nobre, é possível afirmar uma preocupação primeira para o "estado" que o jovem viria a assumir, quer na corte régia, quer nas cortes senhoriais, sendo certo que é sobre este grupo social que é possível recolher mais informes (deixamos de lado a formação dos clérigos, por se tratar de uma especificidade que não cabe no âmbito deste trabalho).

Tendo como modelo o jovem que se prepara para ser rei e do qual deve imanar toda a virtude, em lição bem apreendida nos Espelhos de Príncipes, de que em Portugal salientaremos o de Álvaro Pais (séc. XIV), os restantes nobres deveriam cultivar

\footnotetext{
* Doutorada em História Moderna e Contemporânea pela Faculdade de Letras da Universidade de Lisboa, onde é professora associada com agregação no departamento de História. Entre 1990 e 1996 foi Subdirectora-geral dos Arquivos Nacionais da Torre do Tombo (ANTT) e é, desde 2005, Presidente da Academia Portuguesa de História.
} 
igualmente as boas maneiras e o protocolo, para além de ensaiarem no quotidiano todas as virtudes próprias de um cristão. Em exercício conjunto, todos estes jovens se preparariam igualmente para a guerra, numa variedade de actividades físicas que diariamente praticavam! Entre elas se distinguia, em tempo de paz, o "desporto" da caça (MENDONÇA, 2003)

Se estes informes nos aproximam da formação modelo, em termos morais e práticos, a verdade é que muito pouco se sabe das preocupações com a formação intelectual, nos tempos medievais mais recuados.

Sem dúvida que jovens houve que singraram e atingiram o estatuto de "letrados", sobretudo a partir do século XII, tendo frequentado a Universidade depois de receberem a formação inicial na corte das respectivas famílias. Outros, com menor apetência para a intelectualidade, terão apenas exercitado a leitura e alguns não passaram da iniciação à escrita. Por isso, a grande maioria apenas saberia ler e, eventualmente, assinar.

Apesar disso, não esqueceremos aquele escol que, no final do século XIII, deu vida à corte de D. Dinis, na qual se cultivava sobretudo a poesia e a música, na forma em uso na época.

Mas as grandes alterações, que passaram pelo aprofundamento do gosto pela leitura, a aprendizagem da lição dos grandes filósofos e pedagogos, a recuperação da cultura clássica, a redescoberta do latim, apenas se tornaram efectivas com a dinastia de Avis (COELHO, 2011)!

2. Se o conhecimento da realidade masculina mantém as lacunas traçadas, descortinar o que se passava com a educação de meninas é tarefa ainda mais difícil. Sabemos que, de um modo geral, deviam preparar-se para a futura maternidade, aprender a gestão das tarefas domésticas e alguns desempenhos especiais, como música, costura ou bordados. Para lá disso, apenas os ensinamentos de moral e catequese, para uma formação sólida que, no limite, pudesse garantir futuras alianças políticas ou, simplesmente, nobiliárquicas. De resto, era frequente as meninas nobres deixarem cedo a casa paterna para se deslocarem para a corte das prometidas famílias, quase sempre na sequência da negociação de oportunos casamentos.

É no tempo posterior à rainha Filipa de Lencastre, mais especificamente ao longo do século $\mathrm{XV}$, que descortinamos na corte portuguesa a preocupação de criar e viver um ambiente cultural que vem já carregado dos valores das novas correntes 
humanistas. Se é certo que os valores morais decorriam da aprendizagem e vivência inspirada nos escritos de Santo Agostinho e de S. Jerónimo, é também verdade que os exemplos do saber se recuperavam na filosofia clássica de Sócrates, Platão, Aristóteles, ou de Séneca, não esquecendo os ensinamentos dos tratados de Avicena ou Tomás de Aquino.

A prática de chamar grandes mestres para a instrução dos príncipes justificava a presença na corte, ao longo do século XV, de figuras como Estêvão de Nápoles e Mateus Pisano, Justo Baldino, ou mesmo Frei Gil e D. Jorge da Costa, não esquecendo Cataldo Parísio Sículo (SERRÃO, 1972; MENDONÇA, 1991).

Cultos foram, afinal, todos os príncipes de Avis e disso deixaram testemunho nas obras que nos legaram, de que destacamos o Leal Conselheiro, de D. Duarte, ou a Virtuosa Benfeitoria, de D. Pedro.

Como tal, os reis sucessores de D. João I também não descuraram a educação dos respectivos filhos. Para tanto chamaram, como ficou referido, Mestres humanistas. Note-se que Mateus Pisano chegou a Portugal antes de 1446, quando o príncipe Afonso, futuro Afonso V, que vinha educar, ainda não tinha 14 anos. A mesma situação ocorreu com Estêvão de Nápoles, que terá vindo um pouco antes.

Os cronistas informam que o mesmo D. Afonso V "foy o prymeiro Rey destes Reynos que ajuntou boõs livros, e fez livraria em seus paços” (PINA, 1977, p. 880). Não é de crer que não tivesse chamado outros humanistas para a formação do Príncipe, seu filho e sucessor, D. João II. Foram seus mestres os portugueses, Frei João Rodrigues e o bacharel Vasco Tenreiro e de Itália terá vindo Frei Justo Baldino. Este humanista chegou a Portugal cerca de 1466, quando o Príncipe tinha onze anos. O jovem tivera como aio Diogo Soares de Albergaria, escolhido por "sua fydalguia, bondades e grande saber" e, segundo Garcia de Resende, "tanto que teve entender lhe ordenou logo el Rey seu pay pessoas virtuosas, prudentes e muy examinadas, que delle tivessem cuydado, e que fossem taes de que podesse tomar boa doctrina, e lhe deu bons mestres, que o ensinassem a ler, rezar e latim e escrever...”(p. 3). Um estrangeiro insuspeito, Jerónimo Münzer, viria a escrever que este rei "era um homem instruidíssimo". E um outro humanista, por D. João II chamado a Portugal, registaria, em 1490, “diz-se que são sete as artes liberais. Este sapientíssimo rei parece não só conhecer todas sete (trivium gramática, lógica e retórica - e quadrivium - aritmética, geometria, astronomia e música), mas as nove...(mais a oratória e a poesia)"(MATOS, 1954, 1985; RAMALHO, 1988). 
Servem estes exemplos apenas para ilustrar os cuidados que, na dinastia de Avis, efectivamente se tinham com a educação dos príncipes, sendo certo que com eles faziam grupo, na aprendizagem, muitos jovens nobres. Mas é certo que também as meninas beneficiaram deste despertar para a cultura, como veremos.

3. Outra grande novidade nestes processos de vivência e aprendizagem, na dinastia de Avis, é que eles seriam comuns a homens e mulheres. Todas as princesas deste século $\mathrm{XV}$ foram igualmente cultas e instruídas. Enquanto crianças e adolescentes, terão absorvido conhecimentos, segundo uma educação formal e estruturada, que as preparava para bem responderem aos deveres sociais e para um protocolo de corte a que eram obrigadas (MARTINS, 2009). Algumas mostraram enorme apetência pela valorização intelectual. Disso é exemplo Catarina, a filha mais nova de D. Duarte que, educada por D. Jorge da Costa, terá feito a tradução da Regra de perfeição dos Monges, de Lourenço Justiniano (MENDONÇA, 1991), ou D. Filipa, filha de D. Pedro, conhecida como D. Filipa de Odivelas. Esta senhora fez várias traduções de obras para português, mas deixou igualmente escritos de intervenção política, tais como o "Conselho e Voto da Senhora Dona Felipa filha do Infante Dom Pedro, sobre as terçarias \& guerras com Castela, ou a Practica feita ao Senado de Lisboa em tempo que receava algum tumulto (VICENTE, 2011, p.15). Certamente pode ser considerada um dos expoentes da cultura das mulheres de Avis, devendo ainda destarcar-se nela a vertente moralista e religiosa, que deixou expressa nas Estações e Meditações da Paixão, muy devotas para os que visitam as igrejas quinta feira de Endoenças, obra que viria a ser publicada no século seguinte por D. Catarina, então regente de Portugal por morte de seu marido, D. João III.

4. Esta abertura e apetência para a valorização humana e cultural, verificada em Portugal, ocorria igualmente no ocidente europeu, onde encontramos algumas cortes paradigmáticas. É certo que, como ficou referido, por toda a Europa eram conhecidos os "Espelhos", livros que visavam educar a alta sociedade, sensibilizando sobretudo para os modelos sociais e religiosos, no âmbito das correntes políticas e filosóficas em voga. Nessa literatura moralizadora, príncipes e reis deveriam constituir-se como espelhos de virtudes. A sua presença e actuação deveriam ser reflexo da sua imagem interior, bem formada e que iria apresentar a todos um modelo a seguir. Mas a verdade é que esses manuais de bons usos e costumes não eram dirigidos às mulheres. Seria apenas no 
século XV que a emergência de uma educação/formação feminina, com directrizes próprias e específicas se haveria de materializar. Chegara o momento de consignar em manuais a essência da educação feminina. Requeriam-se "Espelhos de Rainhas"! E o desejo tornou-se realidade! Não foi, certamente, por acaso que a novidade surgiu na corte da Borgonha - corte que, na época, liderava o ocidente, em pompa, etiqueta, cerimonial e protocolo - sobrepondo-se em muito às restantes cortes da "cristandade", nomeadamente à francesa (MENDONÇA, 1995). Com apetência para o novo, a Borgonha haveria de acolher um tema de suprema importância e novidade.

Foi Cristina de Pisano que, nos primeiros anos do século XV (1402?) escreveu o primeiro Tratado de Educação Feminina, que designou por Livro das Três Virtudes. A Insinança das Damas, que viria a ser mais conhecido por Espelho de Cristina. Tal como os Príncipes deveriam aprender nos "Espelhos" de orientação masculina, também Cristina de Pisano oferecia agora às mulheres uma orientação precisa para, elas próprias, se tornarem e aparecerem em sociedade como espelhos de virtudes. Nessa perspectiva, iguala em responsabilidade homens e mulheres, justificando, “... pois o estado real dos grandes senhores é levantado sobre os estados do mundo, é necessário que aqueles, assim homens como mulheres... sejam melhor acostumados que outra gente...”(p. 164); [...] “Que eles possam ser, a seus súbditos... espelho e exemplo de bons costumes..."(p.165)

5. A obra, dedicada a Marguerite de Bourgogne, filha do Duque João Sem Medo e irmã de Filipe, o Bom, difundiu-se, naturalmente, naquela corte e, posteriormente, foi levada para outras, mormente as que, entre si, mantinham mais contactos. Está neste caso a corte portuguesa. É, por isso, muito provável que os escritos de Cristina de Pisano chegassem a Portugal ainda em tempo da rainha Filipa de Lencastre, morta em1415. Se assim aconteceu, sendo um Tratado de moral e bons costumes, foi, certamente de imediato adotado pela Rainha. Se não chegou por essa época, foi pelo menos conhecido depois da infanta Isabel, filha da mesma Rainha e de D. João I, ter casado com o Duque da Borgonha, João, o Bom, em 1430. Ou, na hipótese de alguns, que não comungo, ter vindo com D. Pedro, no seu regresso da viagem pelas sete partidas do mundo, em 1429. Nestes dois últimos casos já não foi conhecido da mãe da "Ínclita Geração".

De um modo ou de outro, certo é que o Espelho de Cristina foi lido e praticado em Portugal, sendo bem conhecido da rainha D. Isabel (1432-1455), mulher de D. Afonso V e filha do infante D. Pedro. Prova da importância que lhe reconheceu para a 
educação de jovens e senhoras, é que o mandou traduzir para português. E não terá sido por acaso que, em 1518, a rainha D. Leonor promoveu a respectiva publicação. Esta rainha, já viúva de D. João II, terá nele reconhecido o valor dos ensinamentos para o "estado de viuvez", que igualmente Cristina contempla.

Independentemente do significado que o trabalho de Cristina de Pisano teve para as "senhoras da nobreza", importa-nos destacar nele uma particularidade: dirige-se a todas as condições sociais. Contudo, respeitando, ela própria, o protocolo vigente, declara: “... se endereçará a nossa lição, primeiramente às Rainhas e Princesas e outras Senhoras... seguindo de grau em grau... cantaremos nossa doutrina em todos os estados das mulheres...” (p. 170)

Depois, no enquadramento geral da temática, assume a papel da Mulher na sua essência declarando que, independentemente da sua condição ou estado, sempre as respectivas actuações devem decorrer do exercício de três virtudes maiores,

"Razão, Direitura e Justiça". E isto, "porque [as virtudes] duram sem fim e são tesouro da alma, que é perpétua. E as outras passam como fumo! E tanto como o espiritual gosto sente sua doçura, as deseja mais que outra coisa mundanal pode ser desejada!"

6. O Espelho de Cristina apresenta-se dividido em três partes, de acordo com o "estado" das mulheres a que se dirige:

\begin{tabular}{|l|l|l|l|l|l|}
\hline I PARTE & $\begin{array}{l}\mathbf{N}^{\mathbf{0}} \text {. } \\
\text { Capit. }\end{array}$ & II PARTE & $\begin{array}{l}\mathbf{N}^{\mathbf{0}} . \\
\text { Capit. }\end{array}$ & III PARTE & $\begin{array}{l}\mathbf{N}^{\mathbf{}} \\
\text { Capit. }\end{array}$ \\
\hline RAINHAS E & XXVII & $\begin{array}{l}\text { SENHORAS E } \\
\text { PRINCESAS }\end{array}$ & XIII & $\begin{array}{l}\text { MULHERES DE ESTADO } \\
\text { MULHERES DO COMUM } \\
\text { POVO }\end{array}$ & XIII \\
& & & & $\begin{array}{l}\text { MULHERES DOS } \\
\text { LAVRADORES }\end{array}$ & \\
& & & & & \\
\hline
\end{tabular}

Para termos uma ideia da temática abordada, indicamos de seguida o assunto de cada capítulo, tentando uma tipologia:

I PARTE - RAINHAS E PRINCESAS (os dois primeiros capítulos são introdutórios, tanto à justificação da obra como à pertinência do tema): 


\begin{tabular}{|c|c|c|}
\hline CAPÍTULOS & TEMÁTICA & ASSUNTO \\
\hline & $\begin{array}{lll}\text { MORALISTAS } & E & \text { DE } \\
\text { ORIENTAÇÃO } & & \end{array}$ & \\
\hline III & & Tipo de tentações \\
\hline IV & & Como resistir às tentações \\
\hline $\mathrm{V}$ & & $\begin{array}{l}\text { Como conseguir bons pensamentos, por amor e } \\
\text { temor de Nosso Senhor }\end{array}$ \\
\hline VI & & $\begin{array}{lllllll}\text { Caracterização } & \text { da } & \text { vida } & \text { activa } & \text { e } & \text { da } & \text { vida } \\
\text { contemplativa } & & & & & & \end{array}$ \\
\hline VII & & $\begin{array}{l}\text { O caminho correcto de uma Princesa temente a } \\
\text { Deus }\end{array}$ \\
\hline VIII & & Como a boa Princesa quererá ter todas as virtudes \\
\hline & DE INTERVENÇÃO & \\
\hline IX & & $\begin{array}{l}\text { Como conseguir a paz entre o Príncipe e seus } \\
\text { vassalos }\end{array}$ \\
\hline $\mathrm{X}$ & & A caridade - como e com quem deve praticá-la \\
\hline & $\begin{array}{l}\text { DE PERFEIÇÃO COMO } \\
\text { RAINHA }\end{array}$ & \\
\hline XI & & A qualidade moral conseguida pela prudência \\
\hline XII & & O modo de viver da princesa "sage" \\
\hline XIII & & $\begin{array}{l}\text { Sete ensinamentos da prudência: } \\
\text { 1. Como relacionar-se com o seu Senhor }\end{array}$ \\
\hline XIV & & $\begin{array}{l}2 \text { - como relacionar-se com os parentes de seu } \\
\text { marido }\end{array}$ \\
\hline $\mathrm{XV}$ & & $\begin{array}{l}3 \text { - como a princesa deve cuidar do "estado e } \\
\text { governança" dos filhos }\end{array}$ \\
\hline XVI & & $\begin{array}{l}4 \text { - como ser discreta com aqueles que sabe que a } \\
\text { não amam }\end{array}$ \\
\hline XVII & & $\begin{array}{l}5-\text { como comportar-se para ser amada e } \\
\text { respeitada pelos súbditos }\end{array}$ \\
\hline XVIII & & $\begin{array}{l}6 \text { - como deve ter "em boa ordenança" as } \\
\text { mulheres da sua corte }\end{array}$ \\
\hline XIX & & $\begin{array}{l}7 \text { - como deve cuidar das suas rendas e da sua } \\
\text { Casa }\end{array}$ \\
\hline & De COMPORTAMENTO & \\
\hline $\mathrm{XX}$ & & $\begin{array}{l}\text { Como deve mostrar-se "grande" e generosa com } \\
\text { os bons }\end{array}$ \\
\hline
\end{tabular}

Hist. R., Goiânia, v. 18, n. 1, p. 53-68, jan. / jun. 2013 


\begin{tabular}{|c|c|c|}
\hline XXI & & $\begin{array}{l}\text { Como deve comportar-se se não pode ser } \\
\text { "grande" nem generosa }\end{array}$ \\
\hline XXII & & $\begin{array}{l}\text { Como deve comportar-se a princesa que fica } \\
\text { viúva }\end{array}$ \\
\hline XXIII & & Princesas viúvas ainda jovens e sem filhos \\
\hline & $\begin{array}{l}\text { O EXEMPLO: ATITUDES } \\
\text { COM AS JOVENS } \\
\text { PRINCESAS }\end{array}$ & \\
\hline XXIV & & $\begin{array}{l}\text { Condições que devem dar-se à princesa recém- } \\
\text { casada }\end{array}$ \\
\hline XXV & & $\begin{array}{l}\text { Comportamentos da "aia" para a manter em "boa } \\
\text { nomeada" }\end{array}$ \\
\hline XXVI & & $\begin{array}{l}\text { Atitude a tomar quando a "nova senhora" tem } \\
\text { desvios nos amores }\end{array}$ \\
\hline XXVII & & $\begin{array}{l}\text { Modelo de carta a enviar a sua senhora, se a } \\
\text { souber desencaminhada }\end{array}$ \\
\hline
\end{tabular}

\section{PARTE: SENHORAS E DONZELAS}

\begin{tabular}{|c|c|c|}
\hline & DE COMPORTAMENTO & \\
\hline $\mathrm{I}$ & & Revisão das três virtudes: Razão, Direitura e Justiça \\
\hline II & & $\begin{array}{l}4 \text { pontos: } 2 \text { para ter e } 2 \text { para recusar. } \\
1 \text { - como devem amar suas Senhoras }\end{array}$ \\
\hline III & & $\begin{array}{l}2 \text { - como devem evitar fazer "grandes gasalhados" } \\
\text { aos homens }\end{array}$ \\
\hline IV & & 3 -a inveja que reina na corte \\
\hline $\mathrm{V}$ & & 3 - como evitar o vício da inveja \\
\hline VI & & $4-$ como evitar maldizer \\
\hline VII & & $\begin{array}{l}\text { Como devem proceder, nunca dizendo mal das suas } \\
\text { Senhoras }\end{array}$ \\
\hline VIII & & Não é próprio difamar ou dizer mal umas das outras \\
\hline IX & & Como devem actuar as baronesas \\
\hline $\mathrm{X}$ & & $\begin{array}{l}\text { Como as que vivem em quintas devem organizar os } \\
\text { seus bens }\end{array}$ \\
\hline XI & & $\begin{array}{l}\text { Conselhos às que exageram nos vestidos, toucados e } \\
\text { corregimentos }\end{array}$ \\
\hline XII & & Conselhos sobre a "soberba" de algumas donas \\
\hline
\end{tabular}




\begin{tabular}{|l|l|l|}
\hline XIII & Comportamentos pedidos às senhoras de religião \\
\hline
\end{tabular}

\section{PARTE - MULHERES}

\begin{tabular}{|c|c|c|}
\hline & DE CONSELHO & \\
\hline Preâmbulo & & $\begin{array}{l}\text { Mulheres de Estado e burguesas; mulheres de } \\
\text { mercadores; mulheres viúvas; moças; velhas } \\
\text { entre as mancebas; moças entre as velhas; } \\
\text { mulheres dos mestres; mulheres servas de casa; } \\
\text { mulheres da mancebia; mulheres honestas e } \\
\text { castas; mulheres dos lavradores; pobres } \\
\text { (homens e mulheres) }\end{array}$ \\
\hline I & & $\begin{array}{l}\text { Revisão do que ficou escrito sobre moral e bons } \\
\text { costumes }\end{array}$ \\
\hline II & & $\begin{array}{l}\text { Mulheres de estado: obrigação de andarem } \\
\text { arranjadas }\end{array}$ \\
\hline III & & Comportamento das mulheres de mercadores \\
\hline IV & & Comportamento de viúvas velhas e mancebas \\
\hline $\mathrm{V}$ & & As virgens \\
\hline VI & & $\begin{array}{l}\text { Atitude das "anciãs mulheres" junto das } \\
\text { mancebas }\end{array}$ \\
\hline VII & & Comportamento das mancebas junto das anciãs \\
\hline VIII & & $\begin{array}{l}\text { Como se devem governar as mulheres dos } \\
\text { Mestres }\end{array}$ \\
\hline IX & & Comportamento das servidoras e camareiras \\
\hline $\mathrm{X}$ & & Ensinamentos às mulheres de "sandia" vida \\
\hline XI & & Louvor às mulheres honestas e castas \\
\hline XII & & As mulheres dos lavradores \\
\hline XIII & & Os pobres \\
\hline
\end{tabular}

Esta terceira e última parte inclui, no capítulo XIV, a conclusão do trabalho. Nele, Cristina despede-se, acreditando que a sua obra,

“... será assoelhada, espargida e publicada em todas as terras...[apesar de estar] em língua francesa... não fica por tanto vaga e não proveitosa... [antes] durará no século sem descaimento, por diversos trelados... a verão e ouvirão muitas valentes Senhoras e mulheres de autoridade, no tempo presente e no que háde vir...". 
7. Tal como Cristina o desejou, assim aconteceria em muitas cortes da Europa, nomeadamente em Portugal e, naturalmente, na Borgonha. Nesta se destaca a própria Duquesa Isabel que, por casamento, para aí se deslocou em 1430, como ficou escrito e aí desempenhou papel fundamental a todos os níveis, incluindo o político. Nascida em 1397, não é seguro que esta princesa de Avis tivesse tido o livro como manual de formação. Mas tê-lo-á eventualmente conhecido ao longo da sua juventude ou, pelo menos, ao chegar à Borgonha. No seu desempenho como Duquesa bem se podem distinguir influências dos ensinamentos de Cristina. Actuou de modo interventivo e decidido, não apenas na política interna, mas também na externa, nomeadamente na relação com o sobrinho, D. Afonso V. A sua actuação foi fundamental na reabilitação de D. Pedro, seu irmão, acusado de traição e morto, em confronto com o rei seu tio, na batalha de Alfarrobeira. Do mesmo modo foi decisiva no futuro dos filhos do Regente morto que, não apenas acolheu na sua Corte, como colocou em lugares destacados noutras cortes europeias. Em toda a sua actuação, fundamentalmente nesta persistente luta, terá agido de acordo com “[...] o amor e temor de Deus Nosso Senhor, porque este é o começo da sabedoria e de que todas as outras virtudes nascem e descendem", conforme ensinou Cristina.

Ao contrário de Isabel, é certo que as suas sobrinhas, principalmente das filhas de D. Duarte, D. Pedro e D. João, foram, desde muito novas, orientadas pelo Livro das Três Virtudes. Como já ficou referido, nas respectivas actuações encontramos marcas destas orientações, não apenas na formação moral e religiosa, mas também no próprio culto do saber, na organização das casas, enfim, nas actuações protocolares e políticas. E, mais que tudo isso, no exercício do modelo de Mulheres íntegras, mas de conduta pautada pelo assumir de uma dignidade própria, forjada numa correcta atitude moral e sedimentada num notável desenvolvimento cultural e intelectual. De entre as que assim se apresentam, e para além das já referidas, podemos ainda lembrar a Duquesa de Viseu, D. Brites, exemplo de mulher inteira, lutando até ao fim pelos objectivos em que acreditava (MARTINS, 2011). No caso, levar ao trono o seu filho, Manuel. Porém, em toda a sua actuação, e considerando os valores da época, nunca estas mulheres deram mostras de ignorância dos seus deveres morais e sociais, em cada momento do respectivo agir. 
8. Retomando a obra de Cristina de Pisano, deixemos de lado as partes II e III, para nos fixarmos na I Parte - Rainhas e Princesas. À luz dos seus ensinamentos, embora sem pretender um exaustivo "estudo de caso", abordarei alguns momentos da actuação de uma princesa de Avis - a rainha D. Isabel, filha do Regente D. Pedro e casada com D. Afonso V. Lembro que foi esta Rainha que mandou traduzir para português a obra de Cristina de Pisano. Não admira, pois, que tivesse seguido a sua lição!

Não cuidaremos aqui da Casa e "donas" que, muito jovem ainda, lhe foram dadas e que geriu num processo que parece ter decorrido dos ensinamentos de Cristina. Não cuidaremos igualmente das suas manifestações de religiosidade, em tudo conformes às de uma "saje princesa". Abordemos apenas a Mulher confrontada com uma tragédia familiar e política.

Casada muito jovem com D. Afonso V, a cronística, nomeadamente Rui de Pina, apresenta-a ornada de virtudes, numa imagem estereotipada e de acordo com o seu estatuto social. São-lhe atribuídas as características de mulher frágil, mas cheia de bondade, piedade, compaixão, amor à verdade, discrição e muita prudência, qualidades coincidentes com as recomendadas no Espelho de Cristina. Lembremos que sete dos capítulos que enunciámos se referem à prudência exigida às Rainhas no seu desempenho familiar e de relação social, "Prudencia... avisará a sajes princesa como a ordem de seu viver seja regida".

O condestável D. Pedro, depois Rei da Catalunha e irmão desta Rainha, escreveu uma obra interessantíssima, que lhe dedicou, onde também a apresenta como um modelo de virtudes. Refiro-me ao texto conhecido como Satira de infelice e felice vida, o qual, quase diria, é o próprio Espelho de D. Isabel. Nele se sistematizam como virtudes e correctos comportamentos da jovem rainha as doutrinas moralistas explanadas por Cristina de Pisano, pois que é caracterizada como,

"muy excelente princesa, muy devota, muy virtuosa e perfecta, de muy perfecta prudência singular discrecion e natural ingenio" . Isabel é igualmente apresentada como honesta e casta e incapaz de qualquer desonestidade. Tal como Cristina de Pisano aconselha, não valorizava louvores e lisonjeadores, desprezava enganos, afastava os maldizentes e os escândalos, desdenhava os que usavam de dissimulação e os que se faziam de loucos. Nesta base, a mulher de D. Afonso V praticava, na sociedade do seu tempo, um conselho de Cristina, “[...] 
Pelos sinais de fora se julga o coração (e não doutra maneira) e, se as obras são boas, dão bom testemunho da boa pessoa e assim do contrário" (cap. XIII).

Rainha discreta, que sabia ouvir com rosto sereno, olhar afável e sempre procurando compreender os momentos difíceis que viveu, Isabel era para quem a rodeava uma companhia amigável. Não se deixava invadir pela ira, por muito fortes que fossem as suas desilusões, nem pelo deslumbramento trazido por eventuais prazeres. Quer dizer que vivia em perfeito equilíbrio, guiada pela regra da "temperança",

“... da qual ela será, per esta maneira de viver, tão abastada e trazida a tal pureza que, em feito nem dito, semblante nem contenença, nem toucado nem jeito nem olhar, não haverá coisa que se possa contra dizer nem reprovar" (cap. XI).

Para lá destes aspectos de comportamento, ético e moral, observemos agora como os ensinamentos de Cristina de Pisano parece terem estado presentes nas actuações políticas da rainha D. Isabel. Foi ela uma figura muito amada, concretamente pelo rei, mas também odiada pela facção que se havia oposto ao seu casamento e era responsável pela tragédia que levara seu pai, o Regente D. Pedro, à morte, em Alfarrobeira. Tenhamos presente que Isabel viveu quase uma dezena de anos acompanhando as lutas de grupos de corte, que se digladiavam buscando supremacia junto do jovem monarca. Em todo este processo político podemos identificar atitudes e comportamentos concordes com a teoria expressa no Livro das Três Virtudes. Exemplifiquemos alguns:

Logo depois do casamento, a intriga de corte, claramente influenciada pelo Duque de Barcelos, procurou o afastamento do Regente D. Pedro. D. Isabel era, pois, mal vista como Rainha, havendo mesmo recurso à difamação para que o rei a repudiasse. E como se comporta ela com os familiares de D. Afonso V? Não há sinais visíveis, na cronística, de reacção adversa de Isabel. Ao contrário, sempre se descortinam nela tentativas de conciliação, lembrando o escrito do Espelho de Cristina,

"Ponhamos que algum deles é ufano e de áspera condição e mal tratável. Ela trabalhará de o adoçar, na melhor forma que puder, segundo sua condição, guardando todavia a honra que a ele pertence, e amará mais todos aqueles que ela souber que seu marido ama" (cap. XIV).

Ao mesmo tempo, Isabel precisava de equilibrar o seu dever de fidelidade para com o marido e rei e com seu pai, em confronto permanente. Foi seu principal objectivo pôr fim às zangas e evitar a tragédia. Não hesitou na mediação, concretizada em diversas missivas enviadas a D. Pedro. Desempenhava-se de acordo com o conselho, 
“... se acontece que alguns dos príncipes, do reino ou da terra... se move contra a pessoa do seu senhor... e ela vê que, de o prender ou lhe fazer guerra, se pode seguir mal a sua terra... a boa senhora, esguardando estas coisas e havendo piedade da destruição do povo, se trabalhará de meter a paz" (cap. IX).

Idêntica actuação tem com o rei. Rui de Pina recria um diálogo entre ambos, no qual a rainha, ajoelhada, fala a Afonso $\mathrm{V}$, recordando a importância de perseverar a família e evitar a guerra. Estaria a praticar o ensinamento que diz, “... amoestará o príncipe seu senhor que esguarde bem sobre isto [guerra], antes que comece, olhando ao mal que se pode seguir e como todo o bom príncipe deve escusar espargimento de sangue e, em especial, sobre seus sujeitos...” (p. 160). Apesar dos esforços, D. Isabel não conseguira evitar a tragédia. Porém, como leal esposa, permaneceu fiel ao seu rei. Morto seu pai, D. Pedro, em Alfarrobeira, certamente se não conformou, mas, como "sage princesa", acreditando nas boas intenções do marido, mais uma vez pôs na prática os ensinamentos de Cristina,

“... e se vir que é bem de lhe dizer alguma coisa, a sajes princesa trabalhará com sajes doçura de o atrair a si. E se vir que é bem de lhe dizer alguma coisa, ela tho tocará à parte, docemente e benignamente: uma vez o admoestará por devoção, outra por piedade que deve haver dela, outra vez em rindo, como se jogatasse com ele. E com isto tho fará dizer por boas pessoas e por seu confessor...E a boa Senhora o escusará disto... nem poderá sofrer ouvir dele falar mal...” (cap. XIII).

Foi certamente deste modo que D. Isabel conseguiu a reabilitação de seu pai. Com ela, conseguiu igualmente que D. Afonso V lhe desse funeral digno, fazendo-o trasladar, em 1455, para o mosteiro de Santa Maria da Vitória, onde repousavam os outros príncipes de Avis.

Isabel morreria pouco depois, mas deixava a marca da Rainha sajes, reveladora de virtudes, com particular realce para a justiça, grandeza de ânimo, prudência e doce engenho, que o mesmo é dizer, as três máximas de Cristina de Pizano: Razão,

\section{Direitura e Justiça.}

9. Em jeito de conclusão, recordemos uma outra Rainha, porventura não menos sofredora do que Isabel, D. Leonor, mulher de D. João II, que continuou a acção de divulgação do Espelho de Cristina, desta vez patrocinando a edição da tradução portuguesa, como ficou referido. Conhecendo muito bem as orientações nele contidas, aquela que haveria de ser a Mãe das Obras de Misericórdia, por ela institucionalizadas 
em Portugal em 1498, reger-se-ia ainda por idênticos procedimentos, seguindo a lição e conselho para as Rainhas Viúvas,

“... não haverá vergonha de visitar os doentes pobres e ricos. E aos pobres dará do seu. E aos ricos honrará e terá cuidado de seus filhos. E em todas as boas coisas se terá tão caridosa e tão doce e assim humana com seus súbditos, que não falem dela senão bem, rogando a Deus por ela.” (p. 153)

\section{CHRISTINE'S MIRROR ( $15^{\mathrm{TH}}$ century)}

ABSTRACT: The second half of the fifteenth century was marked, in Portugal, by the manifested interest in Feminine Education/Instruction. It is from this time onwards that we find a great worry by the protocol and by erudition in the court. One of the most disclosed works was Christine's mirror, or the Book of the Three Virtues, by Christine de Pizan. D. Isabel, wife of D. Afonso V, ordered its translation to Portuguese at around 1450. Later, a different queen, D. Leonor, would make its publication. In this work, we have a problematic approach of women's educations in Portugal and thus we try to compare it with the teachings of this book, presenting some examples that seem to illustrate the reflection of these teachings in some of the performances of some of the women from the Court.

Keywords: Court, Education, Protocol, Mirror, Moral.

\section{EL ESPEJO DE CRISTINA (siglo XV)}

RESUMEN: La segunda mitad del siglo XV se caracterizó, en Portugal, por el interés mostrado por la educación e instrucción femenina. Es a partir de ese momento que encontramos en la corte una gran preocupación por el protocolo y por la erudición. Una de las obras más difundidas fue el El tesoro de la ciudad de las damas o Libro de las Tres Virtudes, escrito por Christine de Pisan. D. Isabel, esposa de D. Afonso V, solicitó la traducción de esa obra al portugués alrededor de 1450. Posteriormente, otra reina, D. Leonor, pediría que hicieran su publicación. En este artículo se hace una aproximación al problema de la educación de las mujeres en Portugal y se trata de enfrentarla con las enseñanzas de ese libro, presentando algunos ejemplos que parecen ilustrar el impacto de esas enseñanzas en la actuación de algunas damas de la Corte.

Palabras clave: corte, educación, protocolo, espejo, moral.

\section{REFERÊNCIAS}

ÁLVARO PAIS, Espelho de reis, trad. de Miguel Pinto de Menezes, Lisboa: 1955.

COELHO Maria Helena da Cruz, D. Filipa de Lencastre, a Inglesa rainha. Lisboa: Academia Portuguesa de História; Matosinhos: Quidnovi, 2011. 
CHRISTINE DE PIZAN, O Livro das Tres Vertudes ou O Espelho de Cristina, edição crítica por Maria de Lourdes Crispim, da tradução quatrocentista de LE LIVRE DES TROIS VERTUS. Dissertação de doutoramento, policopiada, Lisboa, 1995, pp. 147-311. LEAL CONSELHEIRO de D. DUARTE, Leal Conselheiro. Actualização ortográfica, prefácio e notas de João Morais Barbosa, Lisboa: Imprensa Nacional/ Casa da Moeda, 1982.

FREITAS, Isabel Vaz de, D. Isabel de Coimbra - Insigne Rainha, Matosinhos: Quidnovi; Lisboa: Academia Portuguesa de História, 2011.

GARCIA DE RESENDE, Crónica de D. João II e Miscelânea, reimpressão facsimilada da nova edição conforme a de 1798, com prefácio de Joaquim Veríssimo Serrão, 2a . Ed., Lisboa: 1991.

Livro de Montaria de D. João I. Introdução, leitura e notas de Manuela Mendonça, Ericeira: Mar de Letras, 2003.

MARTINS, Maria Odete Sequeira, D. Brites: mulher de ferro (1429-1506), Lisboa: Academia Portuguesa de História/ Vila do Conde: Quidnovi, 2011

, D. Isabel de Portugal, Duquesa da Borgonha. Matosinhos: 2011.

MATOS, Luís de, Nótulas sobre o Humanista Italiano Cataldo Parísio Sículo. A Cidade de Évora, nº. 35-36, ano XI, Jan-Dez, 1954.

, O Ensino na Corte durante a Dinastia de Avis. In O Humanismo Português, Actas do I Simpósio Nacional, Lisboa, 1985.

O ESPELHO DE CRISTINA, intr. de Maria Manuela Cruzeiro, $1^{\text {a }}$. edição fac-similada, Lisboa, 1987.

MENDONÇA, Manuela, D. João II. Um percurso humano e político nas origens da modernidade em Portugal, 2a . edição, Lisboa: Estampa, 1995.

D. Jorge da Costa, Cardeal de Alpedrinha, Lisboa: Colibri, 1991.

D. Leonor, a mais perfeita Rainha, Matosinhos: 2011.

RAMALHO, Américo da Costa, Epistolae et Orationes de Cataldo Parísio Sículo, introdução à edição fac-similada, Coimbra, 1988.

RUI DE PINA, Chronica do Senhor Rey D. Affonso V, in Crónicas de Rui de Pina, introdução e revisão de Manuel Lopes de Almeida, Porto, 1977, p. 880.

SANTOS Maria José Azevedo, Assina quem sabe e lê quem pode, Coimbra, Universidade de Coimbra, 2004.

SERRÃO, Joaquim Veríssimo, A Historiografia Portuguesa: séculos XII-XVI. Lisboa, Verbo, 1972. v.I 
Relações Históricas entre Portugal e a França (1430-1481), Paris, 1975, pp. $15-73$.

VICENTE, Maria da Graça, D. Filipa, A Senhora de Odivelas, Lisboa, Academia Portuguesa de Históira; Vila do Conde: Quidnovi, 2011.

A VIRTUOSA BENFEITORIA: Primeiro Tratado de Educação de Príncipes em português, ed. de Nair de Castro Soares, Coimbra, 1993. 